\title{
THE FORMATION OF METHEMOGLOBIN AND SULFHEMOGLOBIN DURING SULFANILAMIDE THERAPY
}

\author{
By J. S. HARRIS AND H. O. MICHEL \\ (From the Departments of Pediatrics and Biochemistry, Duke University School of Medicine, \\ Durham)
}

(Received for publication April 8, 1939)

Cyanosis almost invariably follows the administration of therapeutic amounts of sulfanilamide (1). This cyanosis is associated with and is due to a change in the color of the blood. The darkening of the blood is present only in the red cells and therefore must be ascribed to one of two causes, a change in the hemoglobin itself or a staining of the red cells with some product formed during the metabolism of sulfanilamide. It is the purpose of this paper to assay quantitatively the effect of sulfanilamide upon the first of these factors-that is, upon the formation of abnormal heme pigments.

A résumé of the literature reveals conflicting data on the state of the hemoglobin after sulfanilamide administration. Many observers have not been able to demonstrate sulfhemoglobin or methemoglobin in any of their cases (2). Mull and Smith (3) reported evidence of inactive hemoglobin as judged by the difference between oxygen capacity and total heme pigment but were unable to find the characteristic spectral bands of either methemoglobin or sulfhemoglobin. Marshall and Walzl (4) found that two of seven cyanotic patients showed slight methemoglobinemia. In the remaining five patients, the oxygen capacity was equivalent to the total iron content of the blood. These bloods appeared dark in spite of the absence of abnormal heme pigments and the writers concluded that some other substance, probably an oxidation product of sulfanilamide, had stained the red cells. Their conclusion received very indirect support from the work of Ottenberg and Fox (5) who showed that a bluish pigment was formed from sulfanilamide in aqueous solutions by the action of ultraviolet light.

Occasional cases of methemoglobinemia of varying intensity have been reported by Paton and Eaton (6), Posner, Guthrie, and Mattice (7), Archer and Discombe (8), and Bensley and Ross (9). Recently, several reports have demonstrated that methemoglobin formation is the usual event during the administration of sulfanilamide. Wendel (10) found spectroscopic evidence of methemoglobin in every blood sample containing over $4 \mathrm{mgm}$. per cent sulfanilamide. Evelyn and Malloy (11) have found that all patients receiving sulfanilamide show methemoglobinemia, although the intensity is usually very slight. Finally Hartmann, Perley, and Barnett (12) found cyanosis associated with methemoglobinemia in almost every patient receiving over 0.1 gram sulfanilamide per kilogram of body weight per day. They believed that the intensity of the methemoglobinemia depended to a slight extent upon the blood sulfanilamide concentration but more upon the peculiarities of the patients. They also noted that the tendency to methemoglobin formation was apparently enhanced by the presence of acute inflammatory processes and a toxic state of the patient. In common with other observers, they found that methemoglobinemia usually disappears within 24 to 72 hours after the administration of the drug is discontinued.

The tendency of sulfanilamide and its derivatives to produce sulfhemoglobinemia has been noted for some time. Colebrook and Kenny (13) found that 3 of 38 patients treated with "Prontosil Soluble" developed sulfhemoglobinemia. Instances of sulfhemoglobinemia after the administration of sulfanilamide have been reported by Paton and Eaton (6) (5 cases), Archer and Discombe (8) (5 cases) and Evelyn and Malloy (11) (4 positive blood examinations). Colebrook and Purdie (14) noted cyanosis in 58 of 106 patients receiving sulfanilamide. Spectroscopic examination of the bloods in 53 of these cases showed methemoglobin in 24 , sulfhemoglobin in 13 , both sulfhemoglobin and methemoglobin in 8 , and absence of abnormal heme pigments in only 8 . Frost (15) has found sulfhemoglobinemia postmortem in a case treated with prontosil and benzylsulfanilamide. 
PLAN OF STUDY

Between May 1937 and May 1938, an attempt was made to obtain frequent blood specimens of all patients receiving sulfanilamide in the clinics and on the wards of Duke Hospital. The drug was generally given by mouth in equal doses four to six times daily. The blood specimens were drawn, when possible, between three and five hours after the ingestion of the drug and were examined shortly thereafter.

The free whole blood sulfanilamide concentration was determined by the method of Marshall (16). At least two standards were used because of the slight deviations from Beer's law. The bloods were examined qualitatively for the presence of abnormal pigments (17). The absorption spectra were inspected through a hand spectroscope for abnormal bands in the red region. The alpha methemoglobin band was confirmed by the usual tests (addition of cyanide in all cases, occasionally supplemented by the action of alkalies and reducing agents). The alpha sulfhemoglobin band was checked by its stability to these reagents. The bands were recognized if more than 4 to 6 per cent of the total pigment had been converted to methemoglobin or if more than 1 per cent was present as sulfhemoglobin. If the abnormal bands were detected, the bloods were subjected to quantitative spectrophotometric examination (17). The method for methemoglobin depended either on the ratio of the extinctions of oxyhemoglobin and cyanmethemoglobin at wavelengths of $575 \mathrm{~m} \mu$ and $560 \mathrm{~m} \mu$ or on the specific change in absorption at a wavelength of $634 \mathrm{~m} \mu$ upon the conversion of methemoglobin to cyanmethemoglobin. The method for sulfhemoglobin depended upon the ratio of the extinctions of sulfhemoglobin and oxyhemoglobin at wavelengths of 540 and $560 \mathrm{~m} \mu$. All quantitative determinations were performed on the Bausch and Lomb Universal Spectrophotometer.

Normal bloods never showed any change in absorption at $634 \mathrm{~m} \mu$ upon the addition of cyanide, nor did the blue product formed from sulfanilamide by the action of ultraviolet light. Since all quantitative determinations were preceded by confirmatory qualitative tests, it is almost certain that the methods were specific for the pigments in question.
RESULTS

\section{A. Methemoglobin formation}

There were 960 blood examinations made on 476 patients. Methemoglobin, in quantities demonstrable by the hand spectroscope, was found in the red cells of 277 or 58 per cent of the patients at some time during the administration of sulfanilamide. The distribution of these patients according to age and sex is shown in Figure 1. The per cent of patients developing methemoglobinemia is roughly equal in the sexes, but is higher in the very young.

\section{Effect of blood sulfanilamide concentration on methemoglobinemia}

All blood specimens were divided into five groups on the basis of their sulfanilamide concentration. In each group, the percentage of bloods which showed methemoglobin (in sufficient quantity to be detected by the hand spectroscope) was calculated. These are plotted against the sulfanilamide concentration of the group in the upper curve in Figure 2. In the 0 to $4 \mathrm{mgm}$. per cent sulfanilamide group, 39 per cent of the specimens were positive. This percentage increased with increasing sulfanilamide concentration until 100 per cent was reached in the group of bloods showing over $16 \mathrm{mgm}$. per cent sulfanilamide.

In each sulfanilamide concentration group, the average methemoglobin value of all bloods within that group was calculated. It can be seen in Figure 2 (lower curve) that the average methemoglobin value varies directly as the sulfanilamide concentration of the blood. It is to be clearly understood that, throughout this study, only those bloods were considered positive for methemoglobin which showed the pigment in amounts detectable by the hand spectroscope. Since quantitative examination was limited to these bloods, the average methemoglobin values herein reported are not true averages. Specimens, calculated as not containing methemoglobin, may have contained up to approximately 0.6 gram per cent. Undoubtedly, the number of positive bloods and the average methemoglobin levels would have been raised if specimens with smaller amounts of methemoglobin had been subjected to quantitative determination. Nevertheless, it is obvious that there is very direct correlation between the average methemo- 


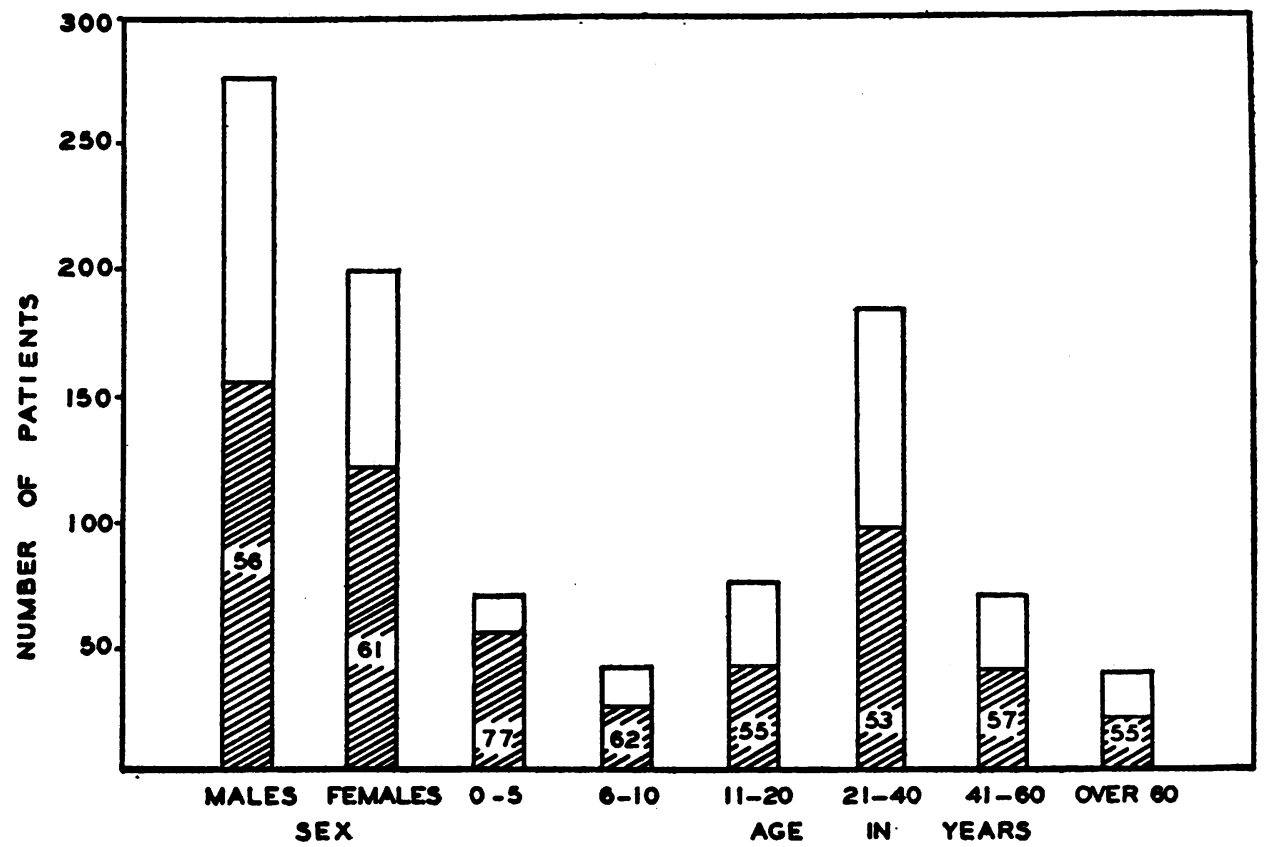

Fig. 1. The Incidence of Methemoglobinemia, According to Sex and Age

Total height of column gives the number of patients studied in each group. The shaded portion gives the number of patients showing methemoglobinemia at some time during therapy. The numbers in the shaded areas refer to the percentage of patients in each group that showed methemoglobinemia.

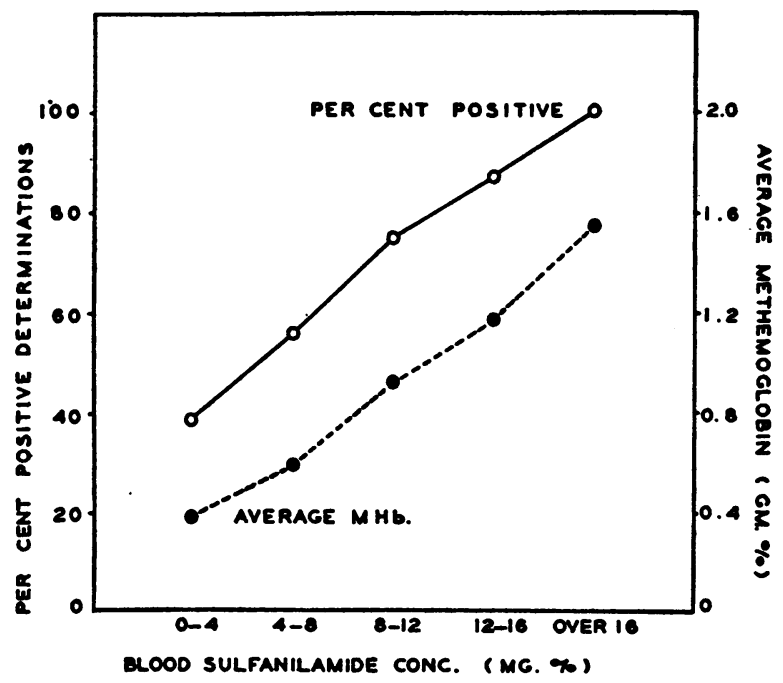

Fig. 2. The Effect of Blood Sulfanilamide ConcenTRATION ON METHEMOGLOBINEMIa

Upper curve: The percentage of blood specimens showing methemoglobin. Lower curve: The average methemoglobin concentration of all blood specimens in each blood sulfanilamide concentration group. globin level and the concentration of sulfanilamide in the blood. At sulfanilamide concentrations in excess of $16 \mathrm{mgm}$. per cent, methemoglobin was invariably present in easily demonstrable quantities. The maximum methemoglobinemia was 5 grams per cent; a conversion of over 40 per cent of the total hemoglobin. This occurred at a blood sulfanilamide concentration of $18 \mathrm{mgm}$. per cent.

\section{Effect of age and sex upon the development of methemoglobin}

It has already been shown that the percentage of patients developing methemoglobinemia is roughly equal in the sexes but is higher in the very young. These conclusions have to be reexamined with regard to the blood sulfanilamide concentrations since it is possible that the drug may have been given in larger amounts and may have reached higher blood levels in a particular group. All the blood specimens in each age and sex group were therefore subdivided according to their sulfanilamide concentration. Table I shows the per- 
TABLE I

The percentage of blood specimens showing methemoglobin, classified according to blood sulfanilamide level, age, and sex

\begin{tabular}{l|c|c|c|c|c}
\hline \hline & \multicolumn{5}{|c}{ Blood sulfanilamide concentration } \\
\cline { 2 - 6 } & 0 to 4 & 4 to 8 & 8 to 12 & 12 to 16 & Over 16 \\
\hline & $\begin{array}{c}\text { mgm. } \\
\text { per cent }\end{array}$ & $\begin{array}{c}\text { mgm. } \\
\text { per cent }\end{array}$ & $\begin{array}{c}\text { mgm. } \\
\text { per cent }\end{array}$ & $\begin{array}{c}\text { mgm. } \\
\text { per cent }\end{array}$ & $\begin{array}{c}\text { mgm. } \\
\text { per cent }\end{array}$ \\
Males........ & 37 & 53 & 84 & 93 & 100 \\
Females...... & 42 & 60 & 64 & 80 & 100 \\
0 to 5 years... & 52 & 66 & 72 & 100 & 100 \\
6 to 10 years.. & 36 & 58 & 53 & 100 & 100 \\
11 to 20 years. & 40 & 56 & 82 & 100 & 100 \\
21 to 40 years. & 40 & 52 & 74 & 67 & 100 \\
41 to 60 years. & 29 & 60 & 92 & & \\
Over 60 years. & 35 & 46 & 60 & & \\
\hline
\end{tabular}

centage of all bloods in each subgroup which were positive for methemoglobin. In Table II is given the average methemoglobin value for each subgroup. At blood sulfanilamide concentrations of 0 to 4 and 4 to $8 \mathrm{mgm}$. per cent (which include

TABLE II

The average methemoglobin concentrations of all blood specimens, grouped according to the blood sulfanilamide level, age, and sex

\begin{tabular}{|c|c|c|c|c|c|}
\hline & \multicolumn{5}{|c|}{ Blood sulfanilamide concentration } \\
\hline & 0 to 4 & 4 to 8 & 8 to 12 & 12 to 16 & Over 16 \\
\hline $\begin{array}{l}\text { Males......... } \\
\text { Females...... } \\
0 \text { to } 5 \text { years... } \\
6 \text { to } 10 \text { years. } \\
11 \text { to } 20 \text { years. } \\
21 \text { to } 40 \text { years. } \\
41 \text { to } 60 \text { years. } \\
\text { Over } 60 \text { years. }\end{array}$ & $\begin{array}{c}\text { mgm. } \\
\text { per cent } \\
0.38 \\
0.38 \\
0.52 \\
0.34 \\
0.44 \\
0.42 \\
0.26 \\
0.30\end{array}$ & $\begin{array}{c}\text { mgm. } \\
\text { per cent } \\
0.58 \\
0.60 \\
0.67 \\
0.70 \\
0.54 \\
0.59 \\
0.58 \\
0.40\end{array}$ & $\begin{array}{c}\text { mem. } \\
\text { per cent } \\
1.09 \\
0.74 \\
0.82 \\
0.68 \\
0.92 \\
1.03 \\
1.05 \\
0.80\end{array}$ & $\begin{array}{l}\text { mem. } \\
\text { per cent } \\
1.49 \\
0.85 \\
1.98 \\
1.24 \\
1.24 \\
0.76\end{array}$ & $\begin{array}{c}\text { mem. } \\
\text { per cent } \\
1.79 \\
0.50 \\
1.45 \\
0.43 \\
1.43 \\
2.03\end{array}$ \\
\hline
\end{tabular}

over 80 per cent of all determinations), there is a greater per cent of positive bloods in the $\mathbf{0}$ to 5 year group than in any other age group. The average methemoglobin concentration, in the same sulfanilamide groups, is also somewhat higher in the very young. Possible differences in the tendency to methemoglobin formation are not obvious in the older age groups or between the sexes.

\section{Effect of duration of therapy and of total dose on methemoglobinemia}

In order to determine the effect of duration of therapy on the intensity of methemoglobinemia, those patients were selected on whom a series of blood determinations were done and who showed methemoglobinemia at some time during the course of therapy. These patients were then divided into groups according to the blood sulfanilamide concentration which they tended to maintain. Thus all patients showing 0 to $4 \mathrm{mgm}$. per cent blood sulfanilamide for a number of days were placed in one group, those having 4 to $8 \mathrm{mgm}$. per cent were placed in another group, those having 8 to $16 \mathrm{mgm}$. per cent in a third and those having over $16 \mathrm{mgm}$. per cent in a fourth. In each group the methemoglobin concentrations of the bloods taken on the first and second days of therapy were then averaged. The same calculations were made for bloods taken on the third and fourth days, fifth and sixth days, etc. These average methemoglobin values are plotted in Figure 3. The four curves represent the four sulfanilamide concentration groups.

At low or moderate concentrations of sulfanilamide, there is a tendency for the average methemoglobin value to decrease with time. In other words, if the blood sulfanilamide concentration is kept at a constant and moderate level for a number of days, the methemoglobinemia will tend to be more pronounced during the first few days and then to gradually fall during the remainder of the time. At very high blood sulfanilamide concentrations (over 16 mgm. per cent), however, the opposite tendency appears to be present. At these concentrations, the methemoglobinemia may increase and, in certain patients, the dose of the drug has to be decreased. The data for the high sulfanilamide level groups is not very clear cut and the curves are irregular, probably owing to the paucity of cases that were maintained at high levels for considerable periods of time.

Hartmann et al. (12) have noted that methemoglobinemia seemed to be more intense when the infection requiring the sulfanilamide therapy was very severe. Although we cannot assay quantitatively this factor, we believe that the correlation between methemoglobinemia and degree of infection may be present only because of co-existing changes in the variables of blood sulfanilamide concentration and duration of therapy. Thus the infection is generally most severe in the first few days of therapy and it is then that the patients 


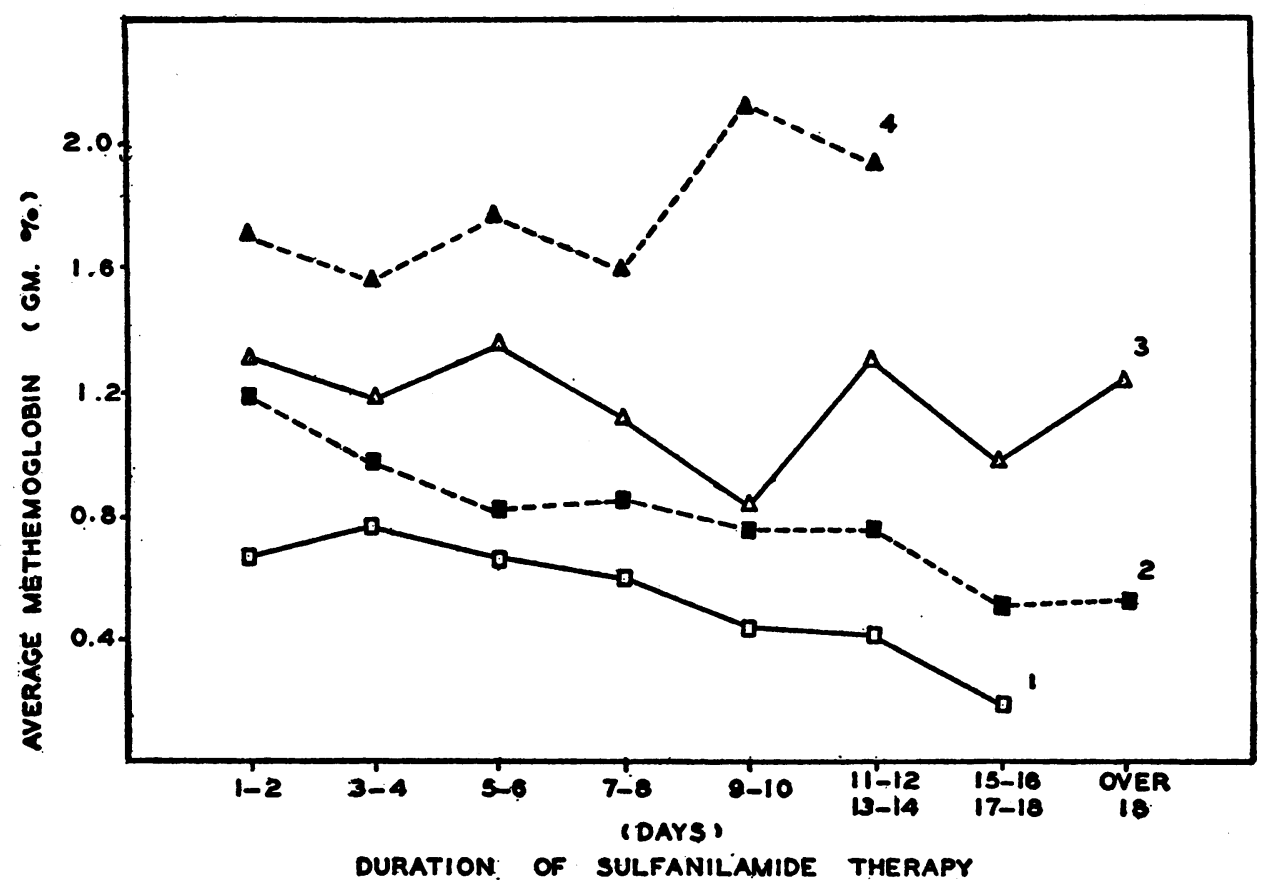

Fig. 3. The Effect of Duration of Sulfanilamide Therapy on Methemoglobinemia

Curve 1: Average methemoglobin concentration of blood specimens obtained from patients maintaining a blood sulfanilamide concentration of 0 to $4 \mathrm{mgm}$. per cent. Curve 2 : Same for sulfanilamide concentration of 4 to $8 \mathrm{mgm}$. per cent. Curve 3: Same for sulfanilamide concentration of 8 to $16 \mathrm{mgm}$. per cent. Curve 4 : Same for sulfanilamide concentration of over $16 \mathrm{mgm}$. per cent.

are usually given larger amounts of the drug. Both factors will cause greater methemoglobinemia during this time.

Since the extent of methemoglobinemia does not increase markedly with the duration of dosage, it is not a cumulative effect of the drug and does not depend upon the total dose of sulfanilamide. The tendency to methemoglobin formation will naturally vary with the total daily dose since the blood sulfanilamide concentration is dependent upon the total daily dose together with other variables such as interval of dose, absorption, kidney function, and fluid output.

\section{The effect of hemoglobin content on methemo- globinemia}

It is possible that the development of methemoglobinemia is favored by the presence of larger concentrations of circulating hemoglobin and that variations in the hemoglobin content of the patients may invalidate the conclusions reached in the preceding paragraphs. To analyze this factor,
647 determinations on patients who showed methemoglobinemia ${ }^{1}$ at some time during their course of therapy were arranged in accordance with the hemoglobin content and the level of blood sulfanilamide. It was found that the percentage of bloods positive for methemoglobin in each sulfanilamide level group did not vary with the hemoglobin content. However, the average methemoglobin concentration showed a tendency to vary in direct relationship to the amount of hemoglobin present, so that the average methemoglobin/total hemoglobin ratio remained rather constant at each blood sulfanilamide level. After this effect was noted, all values in the entire series were altered to terms of per cent of total pigment in the form of methemoglobin and all data were recharted and reanalyzed. The conclusions in regard to the effects of age, sex, blood sulfanilamide level, and of duration of dose were unaltered by this proce-

1 This particular group was chosen since the possibility is present that some patients may be incapable of forming methemoglobin during sulfanilamide administration. 
dure. Apparently the blood hemoglobin levels were rather evenly distributed through the age, sex, and sulfanilamide concentration groups.

\section{The effect of disulfanilamide and sulfapyridine on the development of methemoglobin}

Seventeen patients received courses of disulfanilamide. Fourteen or 83 per cent developed methemoglobinemia during the medication. Of the remaining three, two had received previous courses of sulfanilamide without showing methemoglobin. Of the fourteen showing methemoglobinemia, four had previous courses of sulfanilamide without showing methemoglobinemia. The methemoglobin concentrations reached in the equivalent sulfanilamide and disulfanilamide level groups were distinctly higher in the case of disulfanilamide. It is therefore suggested that the tendency to methemoglobin formation is greater with disulfanilamide than with sulfanilamide.

Preliminary studies on the action of sulfapyridine show that the tendency to cyanosis and to the development of methemoglobin is distinctly less with this substance than with sulfanilamide, although both do occur.

\section{Rapidity of development of methemoglobinemia}

Several patients were given a single oral dose of 3 grams of sulfanilamide or disulfanilamide. Blood samples were taken at hourly intervals for 5 to 7 hours. In contradistinction to the procedure generally followed in this study, all bloods were examined quantitatively for abnormal pigments whether or not the pigment was demonstrable by the hand spectroscope.

\section{Case 1}

Age: 31 years. Weight: $\mathbf{5 5}$ kilos. Diagnosis: Testicular adenocarcinoma. Dose: 3 grams sulfanilamide. Total hemoglobin: 13.1 grams per cent.

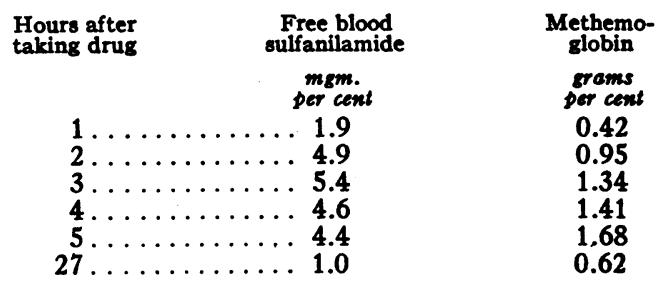

One week later, a similar test was made with 3 grams of disulfanilamide.

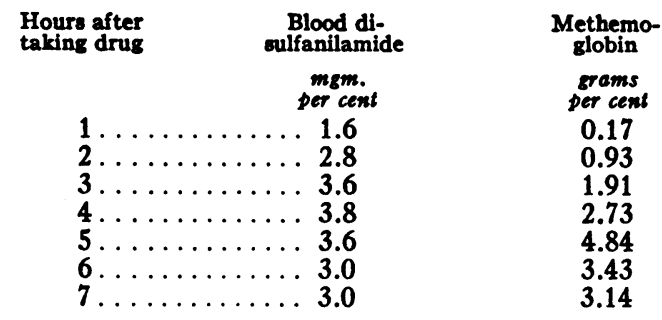

Case 2

Age: 39 years. Diagnosis: Carcinoma of prostate; urinary infection. Dose: 3 grams sulfanilamide. Total hemoglobin: 16 grams per cent.

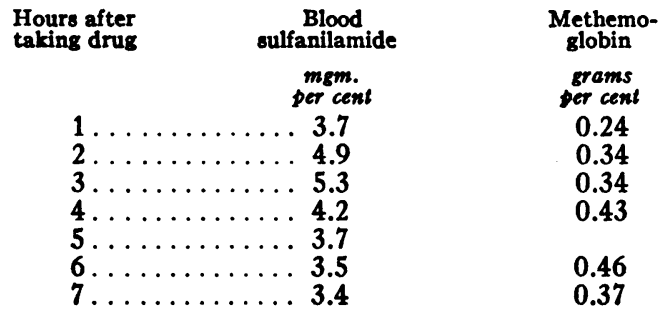

Case 3

Age: 74 years. Diagnosis: Carcinoma of prostate; urinary infection. Dose: 3 grams disulfanilamide. Total hemoglobin: 9.4 grams per cent.

\begin{tabular}{|c|c|c|}
\hline $\begin{array}{l}\text { Hours after } \\
\text { taking drug }\end{array}$ & $\begin{array}{c}\text { Blood } \\
\text { disulfanilamide }\end{array}$ & $\begin{array}{l}\text { Methemo- } \\
\text { globin }\end{array}$ \\
\hline & $\underset{\text { per cent }}{\operatorname{mgm} .}$ & $\underset{\text { per cent }}{\text { grams }}$ \\
\hline 1. & 0.6 & 0 \\
\hline 2 & 1.0 & \\
\hline & 2.2 & \\
\hline & 2.2 & 0 \\
\hline 0 & $\begin{array}{l}2.6 \\
2.6\end{array}$ & $\begin{array}{l}0 \\
0.28\end{array}$ \\
\hline 24. & $\begin{array}{l}2.6 \\
1.8\end{array}$ & $\begin{array}{l}0.37 \\
0.56\end{array}$ \\
\hline
\end{tabular}

In these patients, methemoglobin formation is rapid but does not reach its height until at least 1 to 2 hours after the blood sulfanilamide is maximal. This delay is more prominent with disulfanilamide than with sulfanilamide. In the first case where the disulfanilamide and sulfanilamide were given under comparable conditions, methemoglobin formation was very much more pronounced with disulfanilamide. This is in accord with the conclusions previously deduced. The rate of disappearance of the methemoglobin must be very rapid since, in the first case, the methemoglobin percentage dropped from 1.68 grams per cent to 0.62 gram per cent in the course of 24 hours even though sulfanilamide was still present in the blood. This agrees with our experience that methemoglobin is almost invariably absent within 24 to 72 -hours after the cessation of medication. 


\section{Discussion on methemoglobinemia}

\section{Résumé of literature}

The conversion of hemoglobin to methemoglobin involves the oxidation of the ferrous iron to the ferric state (18). A number of oxidizing substances can rapidly oxidize hemoglobin: ozone, iodine, chlorates, ferricyanides, hydrogen peroxide, permanganates, hydroquinone, hydroxylamine, p-aminophenol, and others (19). In the presence of oxygen, hemoglobin is gradually converted to methemoglobin. In whole unhemolyzed blood this conversion is very slow and must, in part, be delayed by the presence of anti-oxidants or reducing substances. Glutathione, glucose, or unsaturated fatty acids may play such a rôle in the whole blood (20). In the intact organism, methemoglobin is very rapidly reduced to hemoglobin, and it is probable that other reducing systems are of importance.

Clinically, a number of substances have been noted to produce methemoglobinemia in humans and animals. To one group belong obvious oxidizing agents such as potassium perchlorate. The action of these substances is easily explicable since they are sufficiently strong oxidizing agents to perform the conversion in vitro as well as in vivo. Another group of compounds has been reported to cause cyanosis and methemoglobinemia in vivo-e.g., aniline, acetanilid, nitrobenzene (21). These substances are not in themselves oxidizing agents and thus cannot form methemoglobin in vitro from hemoglobin. It has been therefore postulated that these substances are metabolized by the body to some active oxidizing agent which is sufficiently powerful to produce the methemoglobinemia. Ellinger (26) believed that phenylhydroxylamine was the active agent since he found acetylphenylhydroxylamine in the blood of animals poisoned with acetanilid. Lipschitz (27) believed that a similar substance was the active agent in nitrobenzene poisoning and he was able to produce nitrophenylhydroxylamine on shaking dinitrobenzol with frog muscle in vitro. Heubner and his coworkers (28), however, disagreed with these conclusions and believed that $\mathrm{p}$-aminophenol was the active substance. The presence of this substance has been demonstrated in the blood and urine of animals after aniline or acetanilid ingestion by Young (22a), Herrick and Irons (29) and by Lundstein, Meulengracht, and Rischel (23). Heubner and his co-workers (28) also pointed out that nitrophenylhydroxylamine could act only in molar proportions with hemoglobin since the final product was inactive azooxybenzol. On the other hand, p-aminophenol forms a reversible redox equilibrium with quinimine so that one mole of p-aminophenol could produce many moles of methemoglobin. This was found to be true in aniline poisoning by Schwedtke $(30)$. The probable appearance of aminophenols has been demonstrated in vitro through the action of frog muscle on dinitrobenzol by Heubner and Lo-Sing (31) and through the action of rat liver on acetanilid by Michel and Bernheim (32).

It is interesting that the same confusion has arisen in regard to the cause of cyanosis after aniline ingestion as in the question of sulfanilamide cyanosis. Young and his co-workers (22) came to the conclusion that neither acute nor chronic poisoning with acetanilid or aniline is accompanied by the formation of methemoglobin. They believed that phenolic oxidation products stained the red cells and were able to show accumulation of phenolic substances in the blood after aniline poisoning. Lundstein, Meulengracht, and Rischel (23) came to the conclusion that oxidation products of aminophenol stained the red cells in their case of human acetanilid poisoning although they found 18.5 per cent of the hemoglobin had been converted to methemoglobin (by Van Slyke and Hiller method) (24). They found that serum and urine gave positive tests for p-aminophenol and argued that this substance had diffused into the red cells and had become oxidized to dark material. On the other hand, there have been very many reports of methemoglobinemia following ingestion of one of these compounds (21). Part of the discrepancies may be explained by differences in the animals used since Levin (25) has shown that cats, dogs, and rats develop methemoglobinemia on administration of nitrobenzene whereas the rabbit and guinea pig do not. The duration of some of the animal experiments may have been too short to allow the production of methemoglobin.

If an active agent is formed from any of these substances, the extent of methemoglobin formation will depend primarily upon: (a) the speed of formation of the active agent, $(b)$ the speed of interaction between the active agent and hemoglobin, $(c)$ the rate of destruction of the active agent, and $(d)$ the rate of reduction of methemoglobin. Variations in these factors may explain the differences in methemoglobinemia found in patients after the ingestion of acetanilid or aniline. For example, Schwedtke (33) showed that alcohol or ascorbic acid intensifies the toxic action of aniline probably because they prevent the oxidative destruction of the active agent.

It has been demonstrated that 58 per cent of an unselected group of patients receiving sulfanilamide have shown methemoglobinemia, the intensity of which is, on the average, proportional to the concentration of sulfanilamide in the blood. It is probable that many more patients would show methemoglobinemia if sufficient examinations had been made and if our methods detected very small quantities of methemoglobin. Methemoglobin formation in the course of sulfanilamide administration is therefore to be considered as a definite action of the drug, and not as an idiosyncracy on the part of certain patients. Since sulfanilamide cannot oxidize hemoglobin in vitro (unpublished experiments), we were led to postulate that some active agent was formed during the course of metabolism of sulfanilamide by the body which could directly or indirectly cause the oxidation of hemoglobin to methemoglobin. Such mechanism. 
has already been suggested to account for methemoglobin formation after acetanilid or aniline ingestion.

This hypothesis was found to agree very well with the observed data.

1. The extent of methemoglobinemia depends upon the blood sulfanilamide concentration since the speed of the reaction concerned in forming the active agent will naturally depend upon the concentration of substrate. Since sulfanilamide is approximately equally distributed in all body tissues and is stored by none (34), the concentration of sulfanilamide in the active tissue will be reflected by the concentration in the blood.

2. The lag period between the maximum sulfanilamide concentration and the maximal methemoglobinemia after a single dose of sulfanilamide may be, in part, due to the time necessary for the formation and accumulation of sufficient quantities of the active agent.

3. We have observed that the amount of methemoglobin tends to increase as the hemoglobin content increases-so that the average ratio of methemoglobin to hemoglobin remains relatively constant in a series of cases at a definite sulfanilamide level. The speed of the reaction between the active agent and hemoglobin might be increased by greater concentrations of hemoglobin and thus could cause this effect.

4. The absence of a cumulative effect in the production of methemoglobin may be explained by the lability of the active agent (in the event that the agent functions as a catalytic system) and by the ability of the body to reduce methemoglobin back to hemoglobin in a relatively short time. At very high blood sulfanilamide levels, a tendency for a cumulative effect should arise when the speed of formation of the active agent exceeds the body's defenses. This has been noted in certain cases where the dose of sulfanilamide has had to be reduced because of the progressively severe methemoglobinemia. Usually, however, the defenses of the body (destruction of the active agent and reduction of methemoglobin) are mobilized more actively during a course of sulfanilamide since the average methemoglobin tends to diminish with time even though the blood sulfanilamide level remains constant.

5. The variations in the ability of persons to form methemoglobin at definite blood sulfanil- amide concentrations will naturally depend upon the usual biological variations in the several processes concerned. These processes may be influenced by inherent ability, tissue damage (in regard to the reduction of methemoglobin), or by the state of nutrition. (Schwedtke's experiments on the effect of ascorbic acid have already been cited.) It is conceivable that young infants show more methemoglobin than the older groups because of their more active metabolism and the resultant increased quantities of active agent formed.

\section{B. Sulfhemoglobin formation}

Thirty-seven or 7.8 per cent of the 476 patients in the series developed sulfhemoglobinemia at some time during their course of therapy.

\section{Influence of drugs}

Of the thirty-seven patients showing sulfhemoglobinemia, one had received sulfarsphenamine and guaiacol, two had received 0.9 gram of ferrous sulfate daily and two had received 15 grams of magnesium sulfate on the first day of sulfanilamide therapy. One of the latter did not develop the sulfhemoglobinemia until 3 to 6 days after the administration of the magnesium sulfate. This makes it unlikely that the salt was an important factor in the abnormal pigment production in that case. The ferrous sulfate can be eliminated as an important factor since 16 patients of the entire group of 476 patients received ferrous sulfate and only 2 developed sulfhemoglobinemia while 7 showed methemoglobin formation. Neither incidence differs appreciably from the general average for the remainder of the patients. As would be expected, acetanilid seems to predispose to sulfhemoglobin formation since two patients, who had been taking acetanilid and bromides just prior to the sulfanilamide therapy, developed sulfhemoglobinemia. Drugs which did not predispose to abnormal pigment production are neoarsphenamine, bismuth, barbiturates, and morphine derivatives. Specific serum and heat therapy were given to several patients without untoward effects. Constipation was not more prominent in the groups showing abnormal blood pigments.

\section{Influence of blood sulfanilamide concentration}

Attempts to correlate the sulfhemoglobinemia with the blood sulfanilamide concentrations were 
unsuccessful. Of the 88 examinations which were performed on the 37 patients developing sulfhemoglobinemia, 73 per cent were positive for sulfhemoglobin. This percentage was not signifcantly changed when the bloods were divided into groups based on the blood sulfanilamide concentrations. A scatter diagram of the blood sulfhemoglobin levels plotted against the blood sulfanilamide concentration confirms our impression of the lack of correlation between these two values (Figure 4).

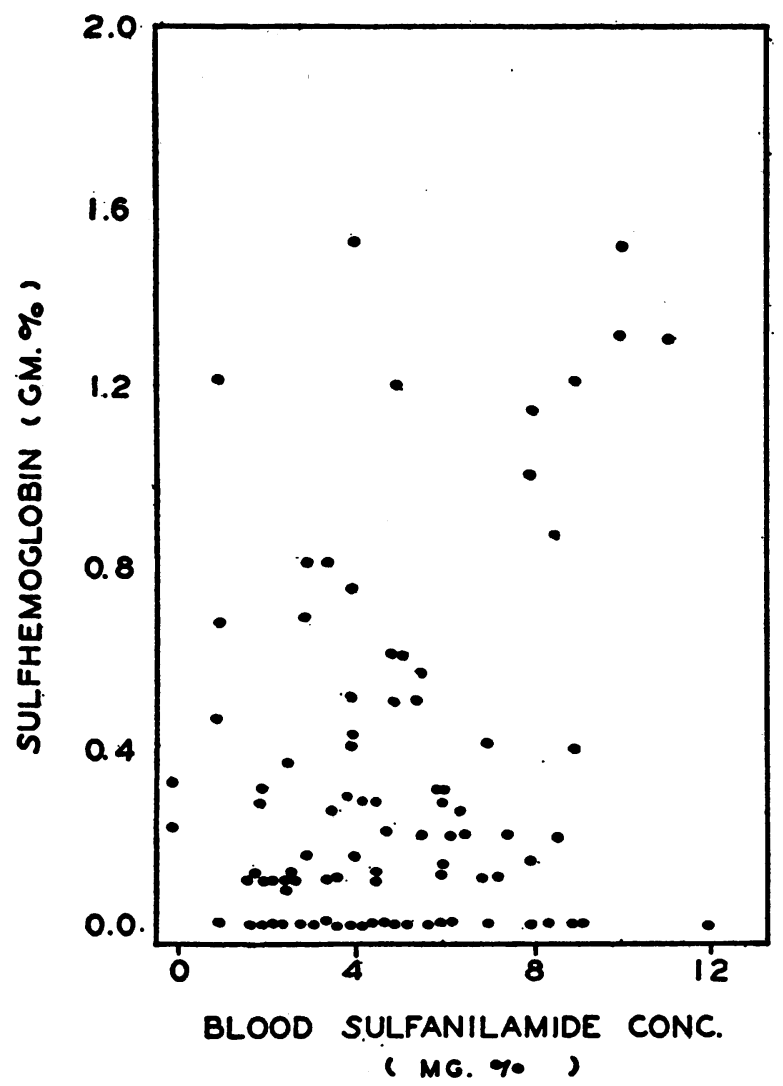

Fig. 4. The Effect of Blood Sulfanilamide ConcenTRATION UPON SULFHEMOGLOBINEMIA

Spot diagram of all determinations on patients who showed sulfhemoglobin at some time during sulfanilamide therapy.

\section{Effect of duration of therapy}

Several blood examinations were made upon 21 of the 37 patients who developed sulfhemoglobinemia. Nine of these patients showed sulfhemoglobin at all examinations while 9 developed sulfhemoglobinemia only during the latter days of therapy (usually after the first week). Three patients developed minimal amounts of sulfhemoglobin during the first week which disappeared while the patients were still taking sulfanilamide. It thus seems that patients are somewhat more likely to show sulfhemoglobin after longer courses of the drug. The question could not be investigated more thoroughly because of the paucity of data.

After the drug is discontinued, the sulfhemoglobin tends to persist for a rather long time. In one case, for example, the sulfhemoglobin concentration dropped slowly from 0.7 to 0.2 gram per cent in the course of 6 days after stopping the sulfanilamide therapy.

\section{Influence of sex and age}

There are no significant differences among the incidences of sulfhemoglobinemia among the sexes. Eight per cent of the males and 7.5 per cent of the females developed sulfhemoglobin at some time during the course of therapy. Likewise it could not be demonstrated that age had any pronounced effect.

\section{Effect of hemoglobin concentration}

A scatter diagram failed to show any correlation between the hemoglobin concentration and the degree of sulfhemoglobinemia in the blood specimens that were obtained on the patients who showed sulfhemoglobin at some time during the course of therapy.

\section{Relationship of sulfhemoglobin and methemoglo- bin formation}

A scatter diagram did not demonstrate any parallelism in the development of sulfhemoglobin and methemoglobin. Patients with intense sulfhemoglobinemia often did not show methemoglobin. The maximum sulfhemoglobin concentration in this series was 1.52 grams per cent (a conversion of 14 per cent of the total pigment). This was associated with 1.8 grams per cent methemoglobin on one occasion and with a negative test for methemoglobin at another time in the same patient. The independence of sulfhemoglobin and methemoglobin formation is also seen in the fact that the direct dependence of methemoglobin on sulfanilamide concentration was present in the sulfhemoglobin group of patients even though the 
sulfhemoglobin concentrations did not show this dependence.

\section{Discussion on sulfhemoglobin formation}

\section{Résumé of the literature on sulfhemoglobin}

The constitution of sulfhemoglobin is not known. Apparently its formation involves the introduction of one atom of labile sulfur and some change in the linkage of the globin to the heme portion of the molecule. This change is irreversible and there is no method for converting sulfhemoglobin back to hemoglobin either in vivo or in vitro without disrupting the molecule (35).

The first definite clinical case of sulfhemoglobinemia was reported by van den Bergh in 1905 (36). At that time, although it was recognized that sulfides in the intestines might be absorbed and cause sulfhemoglobinemia, the explanation for its formation was not clear since it had been demonstrated that the inhalation of hydrogen sulfide in warm blooded animals did not lead to the formation of sulfhemoglobin if the animals survived (37). In 1907, Clarke and Hurtley (38) studied the in vitro formation of sulfhemoglobin from hemoglobin and hydrogen sulfide. They demonstrated that certain reducing substances, such as sodium hydrosulfite, phenylhydrazine, and hydrazine, acted as catalyzers for this reaction and suggested that clinical sulfhemoglobinemia might depend upon the presence of minute amounts of reducing substances in the blood. Later, Wallis (39) actually found reducing substances in the bloods of patients with sulfhemoglobinemia. In 1924, Vogel (40) reported sulfhemoglobinemia in a man whose job involved the production of $\mathrm{p}$-aminophenol from nitrobenzene and who had been using sulfur pills. A reducing substance was found in the patient's serum which was not present in normal serum.

Snapper (41) stressed the importance of aniline derivatives in the production of sulfhemoglobinemia when he reported the presence of sulfhemoglobin in the blood of two patients who had taken large quantities of phenacetin. He demonstrated the formation of sulfhemoglobin in dogs when they were fed both sulfur and phenacetin at the same time. Neither sulfur nor phenacetin was active when fed separately. Snapper believed that phenacetin, or its derivative p-aminophenol, sensitized the red cells to the action of the sulfur. Ivens and van Vollenhoven (42) found that p-aminophenol but not phenacetin could accelerate the formation of sulfhemoglobin from hemoglobin and hydrogen sulfide in vitro. They assumed that phenacetin was metabolized by the body to p-aminophenol which was the active form of the drug.

A number of other reports of sulfhemoglobinemia after the ingestion of acetanilid, phenacetin, or nitrobenzene have appeared (43). One report by Van den Bergh and Revers (44) is interesting in that it demonstrated the appearance of sulfhemoglobin after the ingestion of pyridium, a precursor of sulfanilamide in the chemotherapy of bacterial infections. In all cases, sulfhemoglobin has been noted to persist for long periods after the offending drug had been removed. This behavior is to be contrasted with that of methemoglobin and is probably due to the fact that hemoglobin cannot be reformed directly from sulfhemoglobin.

Archer and Discombe (8) have found that sulfanilamide can accelerate the formation of sulfhemoglobin from hemoglobin and ammonium sulfide in vitro but their work was done at unphysiological acidity and concentration. Paton and Eaton (6) were unable to demonstrate this effect, and we were likewise unsuccessful (unpublished experiments). By analogy to the situation in phenacetin poisoning, we therefore assume that sulfanilamide is converted by the body into some derivative which can accelerate sulfhemoglobin formation from the action of absorbed sulfide compounds on hemoglobin. It is possible that this active derivative is the same one which is responsible for methemoglobin formation.

If these assumptions are true, then the development of sulfhemoglobin after sulfanilamide ingestion depends upon $(a)$ the rate of formation and destruction of the active agent, $(b)$ the intensity of its catalyzing effect, (c) the presence of the necessary sulfide compounds, and $(d)$ the rate of destruction of sulfhemoglobin. A direct relationship between the sulfhemoglobin and sulfanilamide concentrations in the blood would not occur since the factor of the presence of sulfides is quite independent and variable. For the same reason one would not expect a direct correlation between sulfhemoglobin and methemoglobin concentrations. However, there would be a greater tendency to develop sulfhemoglobinemia during long courses of the drug since it is obvious that the longer the accelerator is present in the blood stream, the greater chance there would be of having some peculiarity of intestinal function which would allow the admission of sulfides into the blood stream. Furthermore, since sulfhemoglobin is relatively stable in the body, minute amounts could be formed which would accumulate and become clinically demonstrable only after a period of time. All these deductions are in accord with the data presented.

\section{Other blood pigments}

In several blood samples it was noticed that there was a diffuse darkening of the entire blood 
with particular absorption in the red region of the spectrum. The maximum of this absorption was at $670 \mathrm{~m} \mu$. The plasma, however, was not abnormal so that the pigment was probably not hematin or methemalbumin. The absorption was not changed by reduction with hydrosulfite or by the addition of cyanide (remembering that the blue photo-oxidation product of sulfanilamide is destroyed by hydrosulfite). The pigment giving this absorption was unstable and faded in the course of several hours even if blood was kept at $0^{\circ} \mathrm{C}$. A similar pigment has been noted by one of us (H. O. M.) in the blood of occasional patients treated with nicotinic acid or with bromides and acetanilid. These bloods did not contain methemoglobin or sulfhemoglobin. The nature of the pigment is unknown.

\section{The etiology of sulfanilamide cyanosis}

The question as to whether the cyanosis is entirely due to hemoglobin derivatives is not within the scope of this paper. Cyanosis cannot be quantitated, and it depends on many variables besides the color of the blood. The difficulty becomes insurmountable when dealing with negroes who make up a large part of our series. Furthermore, the extent of methemoglobinemia or sulfhemoglobinemia necessary to produce cyanosis is not known. The consensus of opinion seems to be that a relatively large amount of methemoglobin must be present but Bensley, Rhea, and Mills (45) have recently reported two cases of idiopathic familial methemoglobinemia with cyanosis at times when the concentration of methemoglobin was quite low. In one of these cases, cyanosis was present when the methemoglobin was only 0.7 gram per cent and the total pigment was 14.4 grams per cent. The per cent of total pigment in the form of methemoglobin was therefore less than 5 per cent, and the blood would appear normal on spectroscopic examination to all but the very trained observer. No other cause for cyanosis could be demonstrated in this case. Since the alpha sulfhemoglobin band is some three times as strong in intensity as that of methemoglobin, it would take far smaller quantities of sulfhemoglobin to produce cyanosis.

With these restrictions it is our impression, however, that the cyanosis does not parallel the methemoglobin level in some cases. It may be that some product of sulfanilamide metabolism may stain the red cells-perhaps the breakdown products of the active agent which we have postulated. The important fact remains that the incidence of methemoglobinemia and sulfhemoglobinemia points to the appearance of a physiologically active substance and not to the metabolism of sulfanilamide directly into inactive colored compounds.

\section{SUMMARY}

There were 960 blood samples from 476 patients receiving sulfanilamide examined for free sulfanilamide content, methemoglobin, and sulfhemoglobin. In the 277 patients who had methemoglobinemia and in the 37 patients who had sulfhemoglobinemia at some time, as demonstrable by the hand spectroscope, quantitative spectrophotometric determinations were made.

The percentage of bloods which showed methemoglobin was highest in the group that had high sulfanilamide content. The average methemoglobin value of all bloods was proportional to the sulfanilamide concentration. Methemoglobinemia did not depend upon sex, but was somewhat more frequent and more pronounced in the very young. The average methemoglobin concentration tended to diminish with increasing duration of therapy at constant blood sulfanilamide levels up to $8 \mathrm{mgm}$. per cent but at higher sulfanilamide concentrations there was a tendency for the methemoglobin to increase with time. After a single dose of sulfanilamide, the maximal methemoglobinemia occurred several hours after the blood sulfanilamide had reached its peak.

Sulfhemoglobinemia was more frequent after long courses of sulfanilamide, but did not bear any relationship to age, sex, or the concentration of sulfanilamide or methemoglobin in the blood.

On the basis of these findings, it is postulated that an active substance is normally produced in the course of sulfanilamide metabolism which causes the production of methemoglobin ${ }^{2}$ and sulfhemoglobin. The statistics presented are found to agree with the concept that methemoglo-

2 We have demonstrated the formation of such an active substance when surviving tissues react with sulfanilamide in vitro. These experiments will be published. 
binemia depends upon the balance of the following reactions : formation of the active agent, oxidation of hemoglobin under the influence of the active agent, and reduction of methemoglobin by the body.

\section{BIBLIOGRAPHY}

1. Alyea, E. P., Daniel, W. E., and Harris, J. S., Sulfanilamide therapy in gonorrhea and its complications. South. M. J., 1938, 31, 395.

Holman, W. L., and Duff, G. L., Sulphanilamide and similar compounds in chemotherapy. Am. J. M. Sc., 1938, 195, 379.

Long, P. H., and Bliss, E. A., Toxic manifestations of sufanilamide. Ann. Surg., 1938, 108, 808.

2. Chesley, L. C., Cyanosis without sulf- or methemoglobinemia in patients receiving sulfanilamide treatment. J. Clin. Invest., 1938, 17, 445.

Banks, H. S., Serum and sulphanilamide in acute meningococcal meningitis; preliminary survey based on 113 cases. Lancet, 1938, $2,7$.

3. Mull, J. W., and Smith, J. T., Effect of sulfanilamide on the oxygen capacity of the blood. J. A. M. A., 1938, 110, 439.

4. Marshall, E. K., Jr., and Walzl, E. M., On the cyanosis from sulfanilamide. Bull. Johns Hopkins Hosp., 1937, 61, 140.

5. Ottenberg, R., and Fox, C. L., Jr., Explanation for the cyanosis of sulphanilamide therapy. Proc. Soc. Exper. Biol. and Med., 1938, 38, 479.

6. Paton, J. P. J., and Eaton, J. C., Sulphaemoglobinaemia and methaemoglobinaemia following administration of p-Aminobenzenesulphonamide. Lancet, 1937, 1, 1159 and 1369.

7. Posner, I., Guthrie, N. W., and Mattice, M. R., Formation of abnormal blood pigments as complication of sulfanilamide therapy. J. Lab. and Clin. Med., 1938, 23, 804.

8. Archer, H. E., and Discombe, G., Sulphaemoglobinaemia; its cause and prevention with special reference to treatment with sulphanilamide. Lancet, 1937, 2, 432.

9. Bensley, E. H., and Ross, J. B., Methaemoglobinaemia due to sulphanilamide therapy. Canad. M. A. J., 1937, 37, 62.

10. Wendel, W. B., Methemoglobin determination; clinical method. J. Lab. and Clin. Med., 1938, 24, 96.

11. Evelyn, K. A., and Malloy, H. T., Microdetermination of oxyhemoglobin, methemoglobin and sulfhemoglobin in a single sample of blood. J. Biol. Chem., 1938, 126, 655.

12. Hartmann, A. F., Perley, A. M., and Barnett, H. L., A study of some of the physiological effects of sulfanilamide. II. Methemoglobin formation and its control. J. Clin. Invest., 1938, 17, 699.

13. Colebrook, L., and Kenny, M., Treatment of human puerperal infections, and of experimental infections in mice, with prontosil. Lancet, 1936, 1, 1279.
14. Colebrook, L., and Purdie, A. S., Treatment of 106 cases of puerperal fever by sulphanilamide (streptocide). Lancet, 1937, 2, 1237.

15. Frost, L. D. B., Sulphaemoglobinaemia following anti-streptococcal chemotherapy. Lancet, 1937, 1, 510.

16. Marshall, E. K., Jr., Determination of sulfanilamide in blood and urine. J. Biol. Chem., 1937, 122, 263.

17. Michel, H. O., and Harris, J. S. (To be published.)

18. Conant, J. B., and Pappenheimer, A. M., Jr., A redetermination of the oxidation potential of the hemoglobin-methemoglobin system. J. Biol. Chem., 1932, 98, 57.

19. Stadie, W. C., Studies on the blood changes in pneumococcus infections. An experimental study of the formation and fate of methemoglobin in the blood. J. Exper. Med., 1921, 33, 627.

20. Conant, J. B., The oxidation of hemoglobin and other respiratory pigments. The Harvey Lectures, 1933, 28, 159.

21. McEllroy, W. S., Methemoglobinemia due to bromoseltzer poisoning. J. A. M. A., 1919, 73, 1927.

Scott, R. W., and Hanzlik, P. J., Poisoning by alcohol "denatured" with nitrobenzene. J. A. M. A., 1920, 74, 1000.

22. (a) Young, A. G., Muehlberger, C. W., and Meek, W. J., Toxicological studies of acute anilin poisoning. I. Experimental studies of acute anilin poisoning. J. Pharmacol. and Exper. Therap., 1926, 27, 101.

(b) Young, A. G., Toxicological studies of anilin and anilin compounds. 2. Hematological studies of anilin poisoning. J. Pharmacol. and Exper. Therap., 1926, 27, 125.

(c) Young, A. G., and Wilson, J. A., Toxicological studies of anilin and anilin compounds. 3. Toxicological and hematological studies of acetanilid poisoning. J. Pharmacol. and Exper. Therap., 1926, 27, 133.

23. Lundstein, E., Meulengracht, E., and Rischel, A., Chronic acetanilid poisoning as result of continuous use of "mixed headache powders," or similar compounds. Acta Med. Scandinav., 1938, 96, 462.

24. Van Slyke, D. D., and Hiller, A., Gasometric determination of methemoglobin. J. Biol. Chem., 1929, 84, 205.

25. Levin, S. J., Shoe-dye poisoning. Relation to methemoglobin formation; report of case in 2 year old child. J. A. M. A., 1927, 89, 2178.

26. Ellinger, $P$., Ueber den Mechanismus der Methaemoglobinbildung durch Acetanilid und seine Abkoemmlinge. Ztschr. f. physiol. Chem., 1920, 111, 86.

27. Lipschitz, W., Mechanismus der Giftwirkung aromatischer Nitroverbindungen, zugleich ein Beitrag zum Atmungsproblem tierischer und pflanzlicher Zellen. Ztschr. f. physiol. Chem., 1920, 109, 189.

28. (a) Heubner, S., Studien ueber Methaemoglobinbildung. 3. Ueber den Zusammenhang zwischen 
chemischer Konstitution und Wirkung. Arch. f. exper. Path. u. Pharmakol., 1913, 72, 241.

(b) Heubner, W., Meier, R., and Rhode, H., Studien ueber Methaemoglobinbildung. 5. Phenylhydroxylamin. Arch. f. exper. Path. u. Pharmakol., 1923, $100,149$.

(c) Heubner, W., and Schwedtke, G., Versuche zur Theorie der Methaemoglobinbildung durch Anilin. Arch. f. exper. Path. u. Pharmakol., 1936, 184, 80.

29. Herrick, J. B., and Irons, E. E., Chronic acetanilid poisoning with report of a case due to absorption of the drug from an ulcer of the leg. J. A. M. A., 1906, 46, 351.

30. Schwedtke, G., Studien ueber Methaemoglobinbildung. 7. Zur Theorie der Methaemoglobinbildung durch Anilin. Arch. f. exper. Path. u. Pharmakol., 1938, 188, 121.

31. Heubner, W., and Lo-Sing., Studien ueber Methaemoglobinbildung. 11. Dinitrobenzole. Arch. f. exper. Path. u. Pharmakol., 1938, 188, 143.

32. Michel, H. O., Bernheim, F., and Bernheim, M. L. C., The hydrolysis of acetanilide by various tissues. J. Pharmacol. and Exper. Therap., 1937, 61, 321.

33. Schwedtke, G., Studien ueber Methaemoglobinbildung. 9. Einfluss des Alkohols auf die Methaemoglobinbildung durch Anilin. Arch. f. exper. Path. u. Pharmakol., 1938, 188, 130.

34. Marshall, E. K. Jr., Emerson, K., Jr., and Cutting, W. C., The distribution of sulfanilamide in the organism. J. Pharmacol. and Exper. Therap., 1937, 61, 196.
35. Michel, H. O., A Study of sulfhemoglobin. J. Biol. Chem., 1938, 126, 323.

36. Van den Bergh, A. A. H., Enterogene cyanose. Deutsches Arch. f. klin. Med., 1905, 83, 86.

37. Meyer, E., Ueber da's Verhalten und den Nachweis des Schwefelwasserstoffes im Blute. Arch. f. exper. Path. u. Pharmakol., 1898, 41, 325.

38. Clarke, T. W., and Hurtley, W. H., On sulphaemoglobin. J. Physiol., 1907, 36, 62.

39. Wallis, R. L. M., On sulphaemoglobinaemia. Quart. J. Med., 1913, 7, 73.

40. Vogel, K., Sulphemoglobinemia: with report of a case having a definite etiology. Am. J. M. Sc., 1924, $168,89$.

41. Snapper, I., Phenacetin als Ursache fuer Sulfhaemoglobinaemie. Deutsche med. Wchnschr., 1925, 51, 648.

42. Ivens, W. H. J., and van Vollenhoven, J. M., Over De Intraglobulaire Sulfhaemoglobinaemie. Nederl. tijdschr. v. geneesk., 1925, 69, 447.

43. Harrop, G. A., Jr., and Waterfield, R. L., Sulfhemoglobinaemia. J. A. M. A., 1930, 95, 647.

Hanes, F. M., and Yates, A., An analysis of four hundred instances of chronic bromide intoxication. South. M. J., 1938, 31, 667.

44. Van den Bergh, A. A. H., and Revers, E. E., Sulfhaemoglobinaemie nach Gebrauch von Pyridium. Deutsche med. Wchnschr., 1931, 57, 706.

45. Bensley, E. H., Rhea, L. J., and Mills, E. S., Familial idiopathic methaemoglobinaemia. Quart. J. Med., (New Series) 1938, 7, 325. 